\title{
Política de educação profissional no Vietnã: ofertas formativas sob a vigência da integração internacional
}

NguyenThuong Lang

Universidade Nacional de Economia - Vietnã

\section{Resumo}

O artigo apresenta as mudanças ocorridas no paradigma da política de educação profissional do Vietnã durante o processo de mudança de uma economia altamente centralizada para uma economia de mercado orientada para o socialismo em meio a uma proativa integração internacional. Ao usar a metodologia baseada em evidências e a abordagem histórica do processo, demonstra-se como ocorreram as fases de estruturação da política: 1981-1999, 2000-2015 e a partir de 2016. As políticas de educação profissional do Vietnã têm claro objetivo de atender ao plano do Estado e às necessidades do mercado de trabalho.

Palavras-chave: Educação. Educação profissional. Mercado de trabalho. Planejamento. Integração internacional 


\section{Política de educação profissional no Vietnã: ofertas formativas sob a vigência da integração internacional}

\section{Abstract}

The article presents the changes that have taken place in the paradigm of professional education policy in Vietnam during the process of shifting from a highly centralized economy to a market economy oriented towards socialism in the midst of proactive international integration. Using the evidence-based method and the historical approach to the process demonstrates how the policy structuring phases occurred: 1981-1999, 2000-2015 and beyond 2016. The professional education policies of Vietnam have a clear objective to meet the state's plan and the needs of the labor market.

Key words: Education. Vocational education. Labor market. Planning. International integration.

\section{Política de educação profissional no Vietnã: ofertas formativas sob a vigência da integração internacional}

\section{Resumen}

El artículo presenta los cambios en el paradigma de la política educativa en Vietnam durante el proceso de pasar de una economía planificada altamente centralizada a una economía de mercado al socialismo en medio de una integración internacional proactiva. Al utilizar el metodologia basado en la evidencia y el enfoque histórico del proceso, se muestra como ocurrió fases de estructuración de la política: 1981-1999, 2000-2015 y desde 2016. Las políticas de educación profesional de Vietnam, tiene claro objetivo para cumplir con el plan del estado y las necesidades del mercado laboral.

Palabras clave: La educación. La formación profesional. Mercado de trabajo. La planificación. La integración internacional. 


\section{Política de educação profissional no Vietnã: ofertas formativas sob a vigência da integração internacional}

\section{Résumé}

L'article présente les changements dans le paradigme de la politique de l'éducation au Vietnam au cours du processus de passage d'une économie planifiée hautement centralisée à une économie orientée vers le marché vers le socialisme au milieu d'une intégration internationale proactive. En utilisant la méthode basée sur des preuves et l'approche historique du processus, il est affiché comme produit phases de la politique de structuration: 1981-1999, 2000-2015 et aprés 2016. Les politiques de formation professionnelle du Vietnam, a pour objectif clair pour répondre au plan de l'état et les besoins du marché du travail.

Mots-clés: L'éducation. La formation professionnelle. Le marché du travail. La planification. L'intégration internationale.

\section{Introdução}

O Vietnã tem sido modelo de uma dinâmica integração internacional com o resto do mundo desde 2001. A troca bidirecional do comércio, investimentos e outros entre o Vietnã e o resto do mundo tem sido crescente. Este processo traz para o Vietnã uma série de oportunidades e desafios para a educação profissional. A fim de aproveitar todas as oportunidades e superar os desafios, é necessário construir e implementar políticas eficazes de educação profissional.

Durante o período da economia centralizada, antes de 1986, o Vietnã tinha adotado o mesmo modelo de educação profissional da antiga União Soviética. A partir de 1986, período de economia de mercado socialista, que é a combinação de produção industrial com forte expansão do ensino, e é percebida como essencial para que a educação técnica e profissional possa adaptar-se às mudanças na estrutura da economia, a educação profissional assume um novo formato combinando as demandas do mercado de trabalho interno e as pressões internacionais. Em ambos os períodos, a política de educação profissional do Vietnã obteve resultados notáveis, mas também apresentou algumas limitações. Além disso, há fatores decorrentes da integração internacional, como a presença de um grande número de estrangeiros no Vietnã à procura de empregos e a forte concorrência dos bens importados que impulsionam 
a massa de desempregados, que não dispunham de meios adequados para acessar a educação profissional. No período 2002-2015, anualmente, o número de estudantes do ensino médio no Vietnã aumentou de 2,4 a 3 milhões, representando 2,6 a 3\% da população (Figura 1), o que coloca forte pressão sobre a demanda por emprego no mercado de trabalho. Dentro da composição educacional do Vietnã tem ocorrido uma notável desproporção entre a oferta de cursos de graduação e a pós-graduação, a faculdade e a formação técnico-profissional, em comparação com o mundo. No Vietnã, a proporção é de 10:1, 3:0,92 enquanto no mundo a proporção é de 1:4:10 (Tuan, 2016). ${ }^{1}$

Figura 1: Número de estudantes do ensino secundário e médio do Vietnã no período 2002-2015

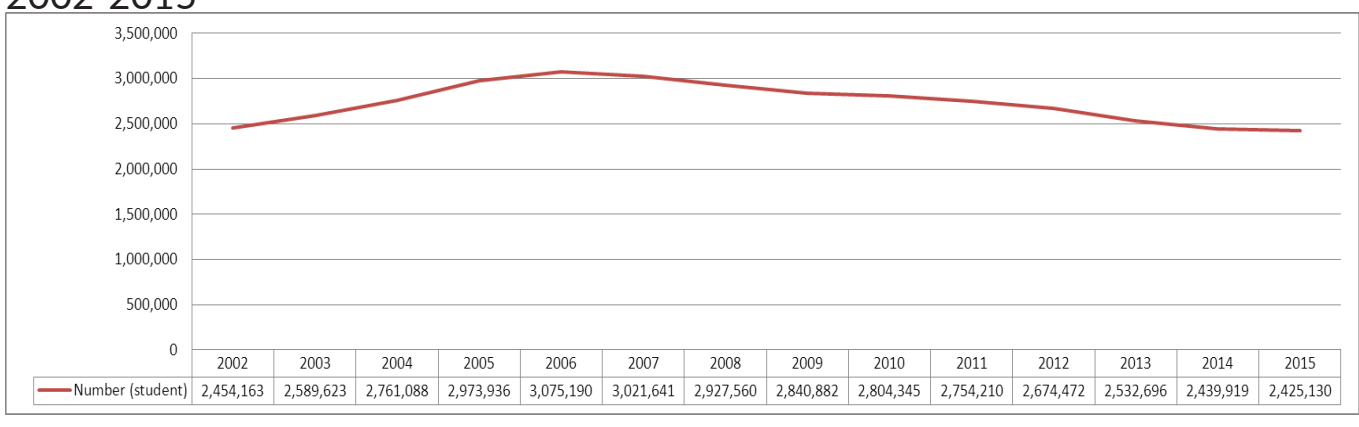

Fonte: Gabinete Geral de Estatística do Vietnã (2016)

A educação profissional é uma etapa da educação que possibilita ao estudante o desenvolvimento de habilidades profissionais específicas após a educação básica, denominada de ensino secundário, e o ensino médio, etapa esta imediatamente anterior à educação superior. A idade para que os estudantes alcancem uma grande mudança em termos físicos e psicológicos varia entre 11 e 18 anos. A política de expansão da educação profissional, por um lado, reduz a pesada pressão para que os estudantes mobilizem seus esforços para fazerem o ensino superior. Por outro lado, contribui na procura por postos de trabalho de modo mais acessivel no atual contexto de alto desemprego no Vietnã, não excluindo estudantes de nível técnico e graduados. Além de ser, uma das iniciativas mais eficazes para reequilibrar a oferta e a demanda no mercado de trabalho, que é o foco das preocupações dos grupos de interesse, como o governo, as escolas, as famílias e os estudantes. No caso do Vietnã, além dos bons resultados de tal política implementada há algumas dezenas de anos, houve alguns obstáculos e limitações que devem ser resolvidos de maneira apropriada.

1 No Vietnã há 10 cursos de graduacões para cada 1,3 cursos de pós-graduacões e 0,92 cursos técnicos. Enquanto que no resto do mundo, há 1 curso de graduacão para cada 4 cursos de pós-graduacões e 10 cursos técnicos. 
Diante do conjunto de compromissos e acordos internacionais de que o Vietnã faz parte, o país abrirá sua economia para os parceiros estrangeiros com o objetivo de inserir no mercado interno novos elementos em termos de comércio, investimento e outros campos relacionados, assim consequentemente, a demanda do mercado de trabalho se modificará. Dessa maneira, a política de educação profissional tem importante papel, que complementa a política nacional de educação e a experiência do Vietnã pode ser referência útil para países que tem similaridades.

Até o momento, ocorreram poucas pesquisas sobre esta questão no Vietnã. Exemplo dessas é a pesquisa sobre educação profissional com enfoque na orientação profissional na região de Hanói (Hoa, 2014) que tem como objetivo observar os impactos do aconselhamento sobre a percepção e aspiração dos alunos sobre a formação profissional. A consulta prévia, eficaz sobre a vocação da região é a forma de promover o papel da política de formação profissional para os estudantes de Hanói, em paralelo com outros canais de informação sobre a educação profissional. Um outro exemplo de pesquisa com esse enfoque enfatiza a escassez de estratégias para a educação profissional no Vietnã (Thuy, 2010), embora haja uma vasta legislação sobre esse tema, a Lei de Educação (1998), Lei de Ensino de Educação Profissional (2006), Lei de Ensino Superior (2012), Lei de Educação Profissional (2014) e outros importantes instrumentos legais relacionados com o ensino profissional. Assim, a estratégia do país para o desenvolvimento da educação, durante o período 2011-2020 estabelece a meta de que, até o ano de 2020 , as instituições de educação profissional terão capacidade para atender cerca de $30 \%$ dos estudantes que concluírem o ensino médio.

\section{Metodologia e dados de pesquisa}

O artigo fornece a avaliação geral sobre a política de educação profissional do Vietnã para deixar claro seus pontos positivos e negativos, especialmente no contexto da dinâmica da integração internacional. As principais dimensões consideradas são o contexto da política de oferta da educação, seu objetivo, conteúdo e desempenho. A partir dessa avaliação, o artigo propõe as soluções para promover os pontos positivos e minimizar os pontos negativos para aperfeiçoar a política no próximo período. A metodologia de análise da pesquisa é baseada nas evidências e na abordagem histórica do processo de mudanças da política de educação profissional, logo, há o relato da educação profissional no Vietnã com um recorte de 40 anos. Os dados explorados para produção do artigo foram coletados a partir de fontes oficiais do governo do Vietnã, tais como, o Escritório de Estatísticas Gerais, Ministério do Trabalho, Previdência e Assuntos Sociais, Ministério da Justiça e Ministério da Educação e Formação. 


\section{A revisão da literatura sobre a política de educação profissional}

A educação profissional é um conceito muito abrangente que pode ser explicado de diferentes maneiras. De acordo com Dictionary.com, a educação profissional é o "treinamento educacional que fornece experiência prática em um campo ocupacional em particular, como agricultura, economia doméstica ou indústria"2. A definição enfatiza a experiência prática em um campo ocupacional particular, de acordo com EQUAVET (2014), o ensino e a formação profissionais referem-se à educação e formação que visa dotar as pessoas de conhecimentos, habilidade e competências exigidos em determinadas profissões ou, de uma forma mais geral, no mercado de trabalho. De acordo com o artigo 3 da Lei Vietnamita sobre Educação Profissional de 2014, a educação profissional tem um significado amplo em duas dimensões, como a educação e a formação. O primeiro considera-o como um nível de educação dentro do sistema educacional que habilita estudantes ao nível primário, secundário, superior e outras formas de educação profissional para os empregados com o objetivo de atender a necessidade direta de recursos humanos na produção, que são realizados em duas etapas, em tempo integral ou em formação continuada. A segunda dimensão é o tipo de ensino para prover conhecimento, competências e atitude profissional necessária para que os estudantes sejam capazes de avaliar a sua empregabilidade após a conclusão dos cursos ou para melhorar suas habilidades profissionais. De acordo com as orientações, a educação profissional é o processo de formação dos conhecimentos profissionais, competências e atitudes para o trabalho com foco nos estudantes com idade entre 11 a 18 anos e difere do ensino superior, que se concentra principalmente em preparar os estudantes para a profissão apenas com o conhecimento profissional específico da área sem temas transversais para aprimorar competências, por exemplo, de convívio social e a educação primária, que tem como objetivo, apenas, eliminar o analfabetismo.

A formação profissional é o que orienta, de fato, em um sentido mais amplo, a política de ensino. A formação profissional, contém os principais elementos como as competências e habilidades oferecidas ao mercado de trabalho, a orientação profissional, a disposição de implementar a política, o uso da aprendizagem no local de trabalho e da participação das partes interessadas, bem como da promoção transparente (OCDE, 2011). Para implementar a política de educação profissional, o sistema de assistência é promovido pelo orientador profissional, conselheiro escolar, professor orientador e conselheiro de estágio (MCAST, 2015). Na abordagem sistemática, a educação profissional consiste na análise do contexto político, estabelecendo a missão e o objetivo, construindo os princípios e efetivando as políticas (SMET, 2011).

2 (http://www.dictionary.com/browse/vocational-education) 
Com base na análise acima, o foco do artigo é o contexto da oferta da política de educação, seu objetivo, conteúdo e o desempenho em cada período de desenvolvimento da política de educação profissional. Estas constroem o quadro analítico para identificar o problema de investigação, compreender a implementação da política e propor as soluções adequadas para a sua melhoria. Além disso, a integração internacional, sendo um fator importante tem muita influência sobre a política do sistema educacional vietnamita como um todo. Segundo este ponto de vista, a política de educação profissional é o sistema de metas, princípios, instrumentos e medidas aplicadas pelo governo para mobilizar os recursos internos e externos para atingir os objetivos em determinado período de tempo.

A política de educação profissional no Vietnã tem sido desenvolvida a partir de diferentes períodos, marcados por momentos decisivos da história do país, que foi sendo aperfeiçoada de forma a articular a educação profissional e o mercado de trabalho.

\section{Período 1: O primeiro período sobre a política de educação profissional: Lei de Educação (1981-1999)}

Esse é o período de lançamento do projeto da política de educação profissional refletida nos regulamentos dos municípios. As principais diretrizes da política de educação profissional do Vietnã, no primeiro momento, foram oficialmente estipuladas pelo Decreto 126 / CP do Governo, emitida em 19 de Março de 1981 sobre o título: "A tarefa orientada para a profissão na escola e o emprego razoável dos estudantes secundário e do ensino médio". Este momento foi aquele em que o país operou dentro do mecanismo centralmente planejado em que o mercado de trabalho não existia; com isso, os empregos para os estudantes foram organizados pelo Comitê de Planejamento do Estado. Durante este período, a cada ano, havia em torno de metade dos estudantes secundaristas, que eram milhões de estudantes, e destes, somente 200 mil alunos completaram seus programas escolares. No entanto, devido à problemas de falta de espaço no ensino superior, nem todos esses alunos foram capazes de continuar a estudar. Consequentemente, algumas centenas de milhares de estudantes tiveram de abandonar as suas escolas para ingressarem no mercado de trabalho não oficial sem as competências profissionais. Na verdade, houve um grande desperdício da força de trabalho na sociedade como um todo, pois o sistema de educação profissional se estabeleceu para fazer frente à escassez do trabalho organizado pelo Governo, melhorando a disponibilidade de aderir à força de trabalho logo após a sua saída do ensino secundário ou médio. Claramente, o caminho correto no contexto de uma reforma abrangente e básica da educação do Vietnã, após a reunião bem sucedida do Norte e do Sul no ano de 1975. 
Para a implementação do Decreto 126 / CP do Governo, o Ministério da Educação era responsável pela educação geral, excluindo o ensino superior naquela época. $A$ carta Circular 33, de 17 de novembro de 1981, detalhou melhor qual seria o foco da educação profissional:

- Estabelecer as necessidades para a formação profissional na escola para educar a atitude do estudante em relação ao emprego e sua percepção correta sobre a profissão; para organizá-los para a prática e para ser absolvido em algumas ocupações principais e específicas dos locais; para compreender sobre a aptidão, tendências da profissão de cada aluno, para incentivar, orientar e atualizar suas capacidades profissionais da forma mais adequada; para mobilizá-los na abordagem para atuarem nas indústrias e nas regiões que precisam de jovens qualificados.

- Fornecer as orientações para a implementação das tarefas da educação profissional, uma vez que deve basear-se na educação abrangente e multifacetada; a tendência para o desenvolvimento cultural, econômico das localidades, a demanda por emprego da força de trabalho na reserva das localidades e do país; e seu conteúdo, forma e metodologia devem ser adequados às características dos alunos em termos de saúde, idade, nível educacional, etc.

- Regulamentar quatro tipos de atividades do ensino profissional como a educação dos sujeitos (cultivo, alimentação animal, mecânica, técnica elétrica e eletrônica), por meio da participação direta nas atividades de produção (bordado, artesanato), introduzindo sobre as profissões novas ocupações nas localidades ou no país) e realizando as atividades extras (fórum, exposição ou intercâmbio entre associações profissionais, pais com alunos).

- Estabelecer o mecanismo de implementação do ensino profissional dentro do sistema educativo nacional desde a atribuição das funções dos diretores das escolas, as responsabilidades dos professores, as funções de gestão do Departamento de Educação das localidades em nível provincial e municipal aos ministérios e outras agências relacionadas. O Ministério da Educação foi responsável por acumular a experiência, elaborar o currículo e fornecer os materiais de aprendizagem das tarefas de implementação.

A Lei da Educação em 1998 é o primeiro marco legal da educação no Vietnã a qual estipula que a educação geral contém 2 níveis de ensino tal como a escola secundária que, variando do $6^{\circ}$ ao a $9^{\circ}$ ano, ou da idade de 11 a 15 anos e o ensino médio, que varia entre $10^{\circ}$ ao $12^{\circ}$ anos ou desde os 16 aos 18 anos (artigo $22^{\circ}$ ). Após a conclusão de cada nível de ensino, é concedido aos alunos os diplomas de ensino secundário ou de ensino médio. $O$ ensino secundário profissional é realizado em um período de 3 a 4 anos de estudos para os alunos com diploma de ensino secundário e de 1 a 2 anos de estudos para aqueles com diploma de ensino médio. A formação profissional é conduzida em menos de 1 ano para o programa profissional de curta duração ou programa pré-profissional, ou de 1 a 3 anos de longa duração para o 
ensino secundário e médio (artigo 28). A Lei também possibilitou a criação de uma instituição independente relacionada com a educação profissional que é o Centro de Técnicas Gerais e Orientação de Carreira (Artigo 26). Segundo a Lei, existem diversas instituições de educação profissional (artigo 32). São escolas profissionais do ensino secundário e instituições de educação profissional, incluindo as escolas de formação profissional, os estabelecimentos de ensino secundário profissional, os centros de formação profissional e as classes de formação profissional. As instituições de formação profissional podem ser organizadas de forma independente ou ligadas a unidades de produção, empresas e outras instituições de ensino. Além disso, mostra os objetivos do ensino profissional não apenas no conhecimento, da formação prática, na capacidade de participar da produção e no serviço, mas também na ética profissional, na consciência disciplinar, nos hábitos industriais, na saúde física, na auto-empregabilidade e na capacidade de um estudo mais aprofundado para melhorar as qualificações profissionais (artigo 29). Além disso, o conteúdo e metodologia de educação profissional, o programa de educação e o diploma e concessão de certificados são levados em consideração na lei. A Lei habilitava os gestores das instituições de educação profissional a estabelecer os currículos e tomar decisões sobre a produção de livros didáticos e conceder os diplomas ou certificados para os alunos que concluíssem o ensino profissional, após a aprovação nos exames específicos.

Os resultados da educação profissional neste período resultaram na mudança no currículo das escolas, acrescentando o tema "orientação profissional" à lista das disciplinas obrigatórias. Alguns centros de educação profissional foram criados para apoiar a implementação da política em 8.734 escolas secundárias e 1.687 escolas de ensino médio em nível nacional. Muitos alunos foram capacitados com o entendimento sobre as ocupações nas localidades e tiveram oportunidades de procurar prováveis postos de trabalho. Como resultado, a pressão sobre a matrícula de estudantes do ensino médio nas escolas de ensino superior e o desemprego foram parcialmente minimizados. No entanto, a melhoria da política de educação profissional, para ser compatível com os requisitos relativos aos recursos humanos qualificados na nova fase do desenvolvimento do Vietnã, tem sido a principal preocupação para todos os grupos de interesse. O número de professores de educação profissional, para atender aos objetivos da política na educação geral estava estimado em cerca de 10.000 (Nhung, 2005). De fato, a força dos quadros responsáveis por essa tarefa não atingiu de maneira suficiente em termos quantitativos e não cumpriu a exigência em termos qualitativos (Thuy, 2010).

\section{Período 2: Período entre a Lei de Educação Nacional até a aprovação da Lei de Educação Profissional (2000-2015)}

Nesse período a política de educação profissional gradualmente ganha destaque, sendo indispensável para o país, pois na legislação começam a surgir artigos que 
tratam essa educação de forma independente (dos artigos 28 a 33) da Lei da Educação (versão 1998) e concomitante; há a ampliação de conteúdos na Lei Revisada de Educação em 2005, 2009, 2013 e 2015, dessa maneira, a formação profissional torna-se disciplina obrigatória no currículo do ensino secundário e médio no Vietnã.

A Lei da Educação elaborada em detalhes no Decreto de regulamentação 33 / CTBGDĐT e promulgada pelo Ministério da Educação e Formação, em 23 de Julho de 2003, teve como objetivo melhorar a formação profissional dos alunos do ensino secundário e médio em 5 pontos principais expostos a seguir:

1) melhoria da percepção dos gestores e professores sobre o significado, o propósito, o conteúdo e as medidas para implementar a educação profissional para os alunos do ensino médio e secundário;

2) classificação dos objetivos da construção do currículo, do seu melhoramento, das escolhas dos livros didáticos para alunos e professores, do processo de ensino de todas as disciplinas e da organização das atividades extras em todos os níveis de ensino, do primário ao ensino médio;

3) execução, com seriedade, das atividades da educação profissional em todas as escolas secundárias, de ensino médio e nos centros de educação técnica para compreender a educação técnica baseado nos materiais didáticos publicados pela Editora da Educação, gerida pelo Ministério da Educação e Formação, em paralelo com um grupo alocado em cada escola para conduzir esse tipo de educação;

4) melhoramento da qualidade do ensino profissional e expansão em escala para assistir os estudantes no entendimento e aquisição de competências profissionais . O Departamento de Educação e Treinamento das províncias alocaram em todas as escolas e nos centros de educação técnica, de forma obrigatória, um grupo de planejamento de ensino profissional, para verificação do processo de aprendizado e da evolução dos resultados dos estudantes para assim, serem capazes de conceder o certificado;

5) aquiescer o papel do departamento estadual ou municipal de Educação e Formação e de outras agências estatais relacionadas com a educação profissional, como companhias, indivíduos e organizações da sociedade civil e as suas respectivas unidades do Partido Comunista para construir uma sinergia a fim de atingir os objetivos desta educação.

Nesse período, a Lei da Educação revisada em 2005, 2009, a Lei da Educação de 2013, a Lei do Ensino da Educação Profissional de 2006, a Constituição revisada de 2013, a Resolução 29/NQ-TW 2013 e a Lei da Educação Profissional de 2014, institucionalizaram e melhoraram a regulamentação sobre a educação profissional. Além disso, difere basicamente da Diretiva 33 na qual há mais responsabilidade do 
diretor das instituições. Assim, a autonomia das instituições de educação profissional tem colaborado com o aprimoramento destas Leis.

Até 2010, no Vietnã, foram construídos 300 centros de formação e orientação profissional e ainda centros para a orientação profissional e educação continuada (Thuy, 2010), que proveram formação e orientação profissional para estudantes da educação básica. Durante o período 2011-2014, sob a pressão da crise financeira e da crise econômica global ocorrida a partir de 2008, o desemprego no Vietnã cresceu, dessa maneira, a cada ano surgiram cerca de duas centenas de milhares de formados no ensino médio e graduados sem capacidade de encontrar emprego (Duy, 2015). Alguns destes apresentam apenas seus diplomas secundários ou de nível médio a fim de acessar os centros de educação profissional para obter certificação em alguma área técnica e assim poderem obter um emprego. Esse fato demonstra o grande desperdício para a sociedade, vietnamita, pois o Artigo 13 da Lei da Educação (2005) afirma que o investimento na educação é o investimento para o desenvolvimento, portanto, é necessário muito investimento na educação profissional, a fim de dirimir a grande discrepância existente entre o ensino superior devido à forma inapropriada da condução do ensino profissional ao longo da vida.

Para superar de forma gradual essa discrepância, a Lei de Educação Profissional promulgada em 27 de novembro de 2014 e o Decreto 48/2015 /ND-CP, datado de 15 de maio de 2015, regulou uma nova forma de captar investimento para aprimorar a educação profissional, inclusive com financiamento de países estrangeiros, todavia, paralelamente a esse processo, a visão do estudante da educação básica em relação a profissional deve mudar, pois ao invés de buscar o ensino superior devem se apropriar das oportunidades que a educação profissional pode proporcionar. Consequentemente, a Lei de Educação Profissional introduziu algumas novas formas jurídicas de organização do ensino profissional, excluindo a educação a cargo das localidades (estadual e municipal), possibilitando a educação privada e a educação financiada com capital estrangeiro.

De acordo com o relatório do Departamento Geral de Educação Profissional enviado ao Ministério do Trabalho, Previdência e Assuntos Sociais, no período 2011-2015, apenas $10 \%$ dos alunos do ensino médio buscaram o ensino profissional (Cao, 2016), o restante escolheu o ensino superior ou os cursos para formação de tecnólogos. Dessa maneira, todos os anos, no Vietnã, há cerca de quatrocentos mil estudantes que não conseguem acessar o ensino superior, consequentemente, necessitam da formação profissional (Son, 2014) para terem oportunidades no mercado de trabalho.

Ao final do ano de 2015, havia 1.467 instituições de ensino profissional, e ainda mais 190 escolas profissionais, 290 estabelecimentos de ensino secundário profissional, 997 centros de ensino profissional e outras 1.000 instituições de ensino e formação e de ensino corporativo, que compõem o ensino profissional. Todas as províncias e cidades em todo o país têm suas instituições de ensino profissional e em muitas 
escolas de ensino secundário e superior, foram criadas várias instituições de ensino profissional com instalações modernas (eletrônica, mecânica, dispositivos elétricos, redes de negócios, informática, etc.) para satisfazer a procura crescente de formação profissional (Cao, 2016). No entanto, o ensino profissional nas escolas secundárias e de ensino médio não tem sido eficaz com os projetos de financiamento com capital estrangeiro como da Samsung (Coreia do Sul), Cannon (Japão) e Intel (EUA), devido à suas elevadas exigências de conhecimento técnico em mecânica, eletrônica e produtos de alta tecnologia, o que demonstra que o investimento na melhoria da qualidade da educação profissional deve ser uma prioridade.

Outro fato interessante é que desde o ano de 2014 muitos estudantes do ensino médio não participaram da matrícula universitária, por exemplo, na província de Nghe An, localizada no centro do país e famosa pela tradição de buscar certificação de cursos em todo o Vietnã. Naquele ano, houve a diminuição de 21.159 (cerca de 27\%) pedidos de matrícula universitária em comparação com 2013 (Duc, 2014). Assim, é possível perceber uma mudança da percepção da sociedade em relação à busca por uma forma de educação que aprimore as suas competências profissionais e que não apenas certifique, assim, talvez, este seja um sinal para o desenvolvimento da educação profissional nos próximos anos.

A política de educação profissional para estudantes do ensino médio e secundário no Vietnã entre 1981 e 2015 revelou algumas limitações. Em primeiro lugar, ocorreram algumas mudanças no processo de transição de um mecanismo de planejamento centralizado para uma economia de mercado orientada para o socialismo, logo, a instabilidade política provocou as respostas passivas das escolas secundárias e do ensino médio às mudanças do mercado de trabalho. Em segundo lugar, houve imperfeições na percepção dos legisladores sobre o papel e o efeito de transformação da política de educação profissional no sistema nacional de educação do país como um todo, de modo que os investimentos para a melhoria da política não se mostraram eficientes. A identidade cultural do povo vietnamita que priorizava o ensino superior não tinha sido levada em consideração ao construir e implementar a política de educação profissional. Em terceiro lugar, a relação entre as instituições formadoras e as empregadoras não foram aprimoradas de forma adequada. Em quarto lugar, a relação federativa dos agentes estatais para alcançar os objetivos das políticas em educação profissional, também, não se mostrou eficiente, assim, ocorreu um desperdício de esforços descoordenados na implementação da política.

\section{Período 3: Período posterior a Lei de Educação Profissional de 2016.}

Nesse período há a expectativa de muitos fatores que influenciaram a política 
de educação profissional, pois há na legislação a aproximação das necessidades da educação profissional com os componentes vitais do sistema educacional do Vietnã como um todo. A instituição de ensino profissional se tornará mais eficaz, pois mais de 500 colégios e faculdades tecnológicas foram transferidos do Ministério da Educação e Formação para o Ministério do Trabalho, Previdência e Assuntos Sociais, a partir de $1^{\circ}$ de janeiro de 2017 (Tam, 2016). A qualidade do ensino profissional, talvez, será aperfeiçoada, pois exige a adaptação da política de educação profissional em sintonia com o mercado de trabalho, logo, espera-se um aprimoramento da relação das instituições formadoras com as empresas. A partir de 2016, muitos compromissos internacionais entre o Vietnã e os parceiros comerciais estarão em vigor, de imediato, acordo de livre comércio UE-Vietnã (EVFTA), Associação de Nações do Sudeste Asiático (ASEAN).

Como resultado dessa abertura, a economia do Vietnã está cada vez mais integrada com o resto do mundo e a concorrência para atrair recursos qualificados entre os países membros do ASEAN se fortifica. A partir do acordo de reconhecimento mútuo (MRAs) dentro do ASEAN, o trabalho qualificado de 8 profissões está sendo permitindo que se movimentem livremente nesse bloco econômico, sendo elas: auditor, contador, arquiteto, engenheiro, doutor em medicina, enfermeira, dentista e topógrafo (Secretaria ASEAN, 2015). Todas as barreiras comerciais no Vietnã têm sido eliminadas para melhorar o ambiente de negócios para o empreendedorismo, inclusive no investimento em formação profissional. Obviamente, há grandes oportunidades de aprimoramento para a formação destes profissionais no Vietnã e nos outros países membros da ASEAN. Além disso, em 2016, o governo escolheu como o ano das empresas startup nacionais, logo, com essa ação, espera-se alcançar 1 milhão de empresas com esse modelo de negócio até 2020, 3 milhões até 2025 e até 5 milhões em um próximo período (Lang, 2016). O Vietnã construiu a Lei de Promoção da Pequena e Média Empresa, em 2016, que é um dos aceleradores para o desenvolvimento da educação profissional e o modelo de negócio startup com princípio no e-commerce recebe muito apoio do governo em termos de crédito preferencial, incentivos fiscais e procedimentos administrativos simplificados a partir do Decreto 844, de 2016.

Percebe-se assim, que a sociedade, no Vietnã, tem alterado sua visão na direção de focalizar mais as habilidades profissionais do que apenas a certificação, além disso, o país está em um período com expressiva população de jovens, e necessita de uma política de educação profissional eficaz para mobilizar a força de trabalho para atender o objetivo estratégico, que é basicamente ser um país industrializado orientado para a modernização até o ano 2020 . O alvo é de que $30 \%$ de estudantes estejam efetivamente na educação profissional até 2020, o que deverá ser alcançado, de tal modo, que esses fatores externos e internos possam convergir em para alcançar, a partir da política de educação profissional, as novas bases do desenvolvimento 
econômico.

\section{Discussão e implicações para melhoria da política de educação profissional no Vietnã sob a vigência da integração internacional}

Com base na situação e na avaliação da política de educação profissional no Vietnã desde a primeira vez que se lançou a política em 1981 até ao ano 2016, é possível perceber que a política de educação profissional no país atingiu os objetivos propostos, embora alguns obstáculos e limitações aconteceram como barreiras a serem superadas. Isso significa que todos os recursos em campos específicos, como a educação profissional, devem ser internalizados para que os efeitos dessa política se concretizem e assim superem as barreiras enfrentadas anteriormente. Depreendese das iniciativas relatadas que as recomendações caminham na seguinte direção:

Inserir a educação profissional em uma posição de igualdade de importância em comparação ao ensino básico e superior. Na verdade, é a condição necessária para que os estudantes obtenham o conhecimento pleno das habilidades produtivas e assim, demonstrem conhecimento, capacidades e atitudes atuando no mercado de trabalho. A propaganda para a educação profissional nas escolas secundárias e de ensino médio deve acontecer para chamar a atenção das famílias, escolas e agências estatais, pois por muito tempo, as habilidades profissionais são os critérios mais importantes para se obter empregos com alta compensação.

Melhorar a qualidade da educação profissional por meio do desenvolvimento de centros, programas ou projetos de formação profissional que respondam à elevada procura de competências profissionais que exige o mercado de trabalho, de acordo com os princípios da economia de mercado, os serviços de educação devem ser tratados como um tipo de serviço que apresenta natureza comercial ou de maximização do lucro, portanto, a procura de serviços de formação profissional em termos de conhecimentos, competências e atitudes para o emprego e ambiente de trabalho deve ser um ponto de partida para a concepção do currículo das instituições de educação profissional. A conectividade e a cooperação entre as instituições ou centros de educação profissional e as instituições empregadoras devem ser reforçadas no desenvolvimento do currículo, na metodologia de ensino, na preparação do livro didático e dos materiais de aprendizagem, dessa maneira, no processo de construção dos programas de educação profissional e currículo para cada profissão, mesmo as habilidades específicas, os especialistas, empregadores e práticos devem ser 
aconselhados da forma mais eficaz. Além disso, é importante aplicá-los de forma piloto em pequenos grupos para torná-los perfeitos como política de Estado.

Para emitir a política de educação profissional é necessário estreitar a coordenação entre as agências estatais, as instituições, os centros, os educadores e os práticos para evitar a assimetria da natureza unificada que pode causar problemas durante a sua implementação. Além disso, o mecanismo de coletar todas as opiniões públicas sobre a política para obter uma visão mais ampla de como deve ser implementada essa política, do ponto de vista científico, devese, antes de iniciar a política, fazer a avaliação do impacto do desempenho e do grau de atendimento, assim, é possível compreender claramente a situação dos estudantes e das instituições para conduzir a pesquisa sob as respostas dos alunos e das instituições à política para implementá-la e aprimorá-la.

Os impactos dos compromissos internacionais provenientes dos acordos de livre comércio ou das negociações acordadas internacionalmente constituem o forte impulso para inovar a política de educação profissional do Vietnã. As experiências internacionais do êxito e fracasso da política de educação profissional de outros países devem ser analisadas para servirem de exemplo para os vietnamitas. As técnicas de avaliação comparada da política de educação profissional podem ser utilizadas para fornecer evidências confiáveis para a formulação de políticas, pois quando há a combinação do fator externo e interno na reestruturação da educação profissional para que haja coerência com o mercado pode ser a opção de política estratégica para o caso do Vietnã.

Logo, os acordos Internacionais de livre comércio, também colaboram com o desenvolvimento da educação profissional do Vietnã, pois devido a forte integração que esse ensino tem com a indústria, proveniente da economia de mercado socialista, toda colaboração do mercado vietnamita, em nível de troca de tecnologias ou melhorias de serviços, com os de outros países estará automaticamente aderente a educação profissional. 


\section{Considerações finais}

A política de educação profissional para os estudantes do ensino médio antes de acessarem o ensino superior é uma questão ainda desafiadora para as agências estatais responsáveis pela educação, as localidades, as instituições, as famílias, os estudantes e a opinião pública do Vietnã. Sob forte pressão de integração, que é retratada pelos compromissos internacionais, do acordo de livre comércio e de outras negociações acordadas internacionalmente, a política deverá ser melhorada para atingir o objetivo de formação profissional de $30 \%$ dos estudantes do ensino secundário e médio até 2020 , atualmente o Vietnã tem a modesta participação de $10 \%$ de estudantes.

A política de educação profissional refere-se a várias dimensões relativas à Constituição, à Lei da Educação, ao Direito do Ensino Superior, ao Direito do Ensino Profissional e a outros documentos jurídicos. Durante o processo de transformação de uma economia planificada para um mecanismo de economia de mercado, orientado para o socialismo, os princípios do mercado impactaram na política e obviamente, essa orientação contribuiu para as melhorias necessárias.

A partir do ano de 2016, a política de educação profissional enfrenta vários fatores que podem influenciar o princípio, o conteúdo e a metodologia de implementação, logo, a autonomia das instituições e centros de formação profissional serão o ponto central dessa política. Os compromissos internacionais proporcionam um quadro amplo e certo para melhorar a formação profissional em paralelo com a influência dos fatores internos como a melhoria básica do sistema nacional de educação e formação. Em grande medida, a reestruturação da educação profissional torna-se a opção de política estratégica para o Vietnã sob uma integração internacional próativa, buscando minimizar a distância entre a procura do mercado de trabalho e as capacidades de fornecimento das instituições de educação profissional. 


\section{Referências}

ASEAN Secretariat (2015), ASEAN Economic Community Blueprint 2025. Available in: <http://www.asean.org/storage/2016/03/AECBP_2025r_FINAL.pdf>. Access in: the 8th Dec.2016.

CAO, Nguyen. (2016), The story "redundancy of teachers and vacancy of skilled workers" and the paradox of profession choosing. Available in: <http://giaoduc. net.vn/Giao-duc-24h/Chuyen-thua-thay-thieu-tho-va-nghich-ly-chon-nghepost165050.gd>. Access in: the 5th Dec. 2016.

CHAU, Minh. (2015), Higher education students: Graduation and unemployment. Available in: <https://www.careerlink.vn/cam-nang-viec-lam/tin-tuc-viec-lam/ sinh-vien-:-tot-nghiep-va-that-nghiep>. Access in: the 5th Dec. 2016.

Dictionary.com, Definition, Vocational education. Available in: <http://www. dictionary.com/browse/vocational-education>. Access in: the 7th Dec. 2016.

DUC, Minh. (2014), Nghe An: Decrease by 21,159 applications to take university enrollment examination in comparison with that of the year 2013. Available in: <http://gtvt.nghean.gov.vn/wps/wcm/connect/Web+Content/PORTAL_NA/ TTSK/xh/fb9d718043af02008356c34585cfbca8>. Access in: the 9th Dec. 2016.

DUY, Khuong. (2015), Hundreds of thousands have not get the jobs, it is surprised, isn't it? Available in: <http://vietnamnet.vn/vn/tuanvietnam/hang-tram-ngan-cunhan-thac-si-that-nghiep-khong-ngac-nhien-254227.html>. Access in: the 10th Dec. 2016.

EUROPEAN UNION QUALITY ASSURANCE IN VOCATIONAL EDUCATION AND TRAINING (EQUAVET), (2014) definition. Available in: <www.eqavet.eu/qa/gns/ glossary/v/vocational-education-and-training.aspx>. p. 298. Access in: the 10th Dec. 2016.

HOA, Truong Thi. (2014), Vocational education for high school students in Hanoi region by the vocational counseling, Doctorate in Education Thesis, Vietnam's Academy of Education Science, pp. 28-59, Available in: <http://vnies.edu.vn/ upload/Boiduong/truongthihoa.pdf >. Access in: the 12th Dec. 2016.

LANG, Nguyen Thuong. (2016), Comparing Vietnam's start-up policy with that of other ASEAN countries. Journal of Economics and Development, Volume 10. 2016.

MALTA COLLEGE OF ART, SCIENCE \&TECHNOLOGY (MCAST), (2015), National Vocational Education and Training Policy. Available in: https://ncfhe.gov.mt/en/ 
resources/Documents/Strategy\%20Documents/National\%20Vocational\%20 Education\%20and\%20Training\%20Policy.pdf p.14. Access in: the 7th Dec. 2016.

NHUNG, Tran Van. (2005), Orientation and the tasks of the vocational education in Vietnam's education system. Available in: <http://tainguyenso.vnu.edu.vn/ jspui/handle/123456789/4677>. Access in: the 12th Dec. 2016.

OCDE (2011), OCDE reviews of vocational education and training. Available in: <https://www.oecd.org/edu/skillsbeyondschool/LearningForJobsPointersfor\%20 PolicyDevelopment.pdf>. pp. 5-6. Access in: the 14th Dec. 2016.

PHONG, Le Thanh. (2014), Keeping the higher education diploma in the cabinet to do as a worker, Available in: <http://laodong.com.vn/vieclam-mobile/cat-bangdai-hoc-lam-cong-nhan-270603.bld>. Access in: the 8th Dec. 2016.

SON, Huynh Van. (2014), Profession-oriented task should be truly started at what time? Available in: <https://www.facebook.com/TSTLHuynhVanSon/ posts/823706347682425 >. Access in: the 12th Dec. 2016.

SWAZILAND MINISTRY OF EDUCATION AND TRAINING (SMET) (2011), The Swaziland Education and Training Sector Policy. Available in: <http://planipolis. iiep.unesco.org/upload/Swaziland/SwazilandEducationSectorPolicy2011.pdf>. pp.10-12. ACCESS IN: THE 14TH DEC. 2016.

TAM, Thanh. (2016), More than 500 colleges and secondary colleges are transferred to be managed by the Ministry of Labor, Invalid and Social Affairs. Available in: $<$ http://vnexpress.net/tin-tuc/giao-duc/hon-500-truong-cao-dang-trung-capchuyen-ve-bo-lao-dong-3496782.html >. Access in: the 13th Dec. 2016.

TUAN, Nguyen Anh. (2016), The Development Tendencies of the World Economy up to 2030 and the Solutions for the International Integrations of Vietnam. The presentation at the 5th Vietnamese Studies International Conference "Sustainable development in the context of climate change" organized in Hanoi, Vietnam on the 15-16th Dec. 2016.

THUY, Le Thi Thu. (2010), Vocational education in Vietnam. Available in: <http:// mywork.com.vn/data/files/documents/GDHN.pdf >. Access in: the 13th Dec. 2016.

UNESCO (2012), Technical and Vocational Education and Training (TVET). Available in: <http://www.unesco.org/new/en/education/themes/educationbuilding-blocks/technical-vocational-education-and-training-tvet>. Access in: the 15th Dec. 2016. 
VIETNAM CENTRALLY STANDING BOARD OF COMMUNIST PARTY (2013), The Resolution 29/NQ-TW dated on the 4th November 2013 on Comprehensively and Basically Renovating the Education and Training. Available in: $<$ https://ado.hcmuaf. edu.vn/data/file/V\%C4\%83n\%20b\%E1\%BA\%A3n\%20c\%E1\%BB\%A7a\%20 \%C4\%90\%E1\%BA\%A3ng,\%20c\%C3\%A1c\%20\%C4\%910\%C3\%A0n\%20 th\%E1\%BB\%83/V\%C4\%83n\%20b\%E1\%BA\%A3n\%20c\%E1\%BB\%A7a\%20\%C4\%90\%E1\%BA\%A3ng/BCHTW-NQ-29-04_11_2013-DoiMoiCanBanToanDien GiaoDucDaoTao.pdf>. Access in: the 12th Dec. 2016.

VIETNAM GENERAL STATISTICAL OFFICE (2016), The number of high school students in the period 2002-2015. Available in: <http://www.gso.gov.vn/default_ en.aspx?tabid=782>. Access in the 10th Dec. 2016.

VIETNAM GOVERNMENT COUNCIL (1981), Decision 126/CP dated in 19th March 1981 about "The profession-oriented task in the school and reasonable employment of the students graduated from the secondary and high school". Available in: <http://thuvienphapluat.vn/van-ban/Lao-dong-Tien-luong/Quyetdinh-126-CP-cong-tac-huong-nghiep-trong-truong-pho-thong-su-dung-hocsinh-pho-thong-co-so-pho-thong-trung-hoc-tot-nghiep-43052.aspx>. Access in: the 13th Dec. 2016.

VIETNAM MINISTRY OF EDUCATION (1981), Circular 31-TT dated in the 17th November 1981 about "Guideline on implementation of the Decision of the Government Council about "The profession-oriented task in the school and reasonable employment of the students graduated from the secondary and high school". Available in: <http://thuvienphapluat.vn/van-ban/Giao-duc/Thongtu-31-TT-cong-tac-huong-nghiep-trong-nha-truong-pho-thong-su-dung-hoply-hoc-sinh-pho-thong-tot-nghiep-huong-dan-Quyet-dinh-Hoi-dong-Chinhphu/43891/noi-dung.aspx>. Access in: the 13th Dec. 2016.

VIETNAM NATIONALASSEMBLY (2014), Vietnam's Constitution (Revision 2013). Available in: <http://moj.gov.vn/vbpq/Lists/Vn\%20bn\%20php\%20lut/View _ Detail.aspx? ItemID=28814 >. Access in the 15th Dec. 2016.

VIETNAM NATIONAL ASSEMBLY (1998), Vietnam's Law of Education. Available in: <http://thuvienphapluat.vn/van-ban/Giao-duc/Luat-giao-duc-1998-11-1998QH10-44857.aspx>. Access in: the 15th Dec. 2016.

VIETNAM NATIONAL ASSEMBLY (2005), Vietnam's Law of Education (2005), Amendment and Addition version. Available in: <http://thuvienphapluat.vn/vanban/Giao-duc/Luat-Giao-duc-2005-38-2005-QH11-2636.aspx>. Access in: the 15th Dec. 2016. 
VIETNAM NATIONALASSEMBLY (2009), Vietnam's Law of Education: Amendment and Addition. Available in: <http://thuvienphapluat.vn/van-ban/Giao-duc/Luatgiao-duc-sua-doi-nam-2009-98730.aspx>. Access in: the 15th Dec. 2016.

VIETNAM NATIONAL ASSEMBLY (2012), Vietnam's Law of Higher Education. Available in: <http://www.chinhphu.vn/portal/page/portal/chinhphu/hethongvan ban?mode=detail\&document_id=163054>. Access in the 15th Dec. 2016.

VIETNAM NATIONAL ASSEMBLY (2013), Vietnam's Law of Education. Available in: <http://thuvienphapluat.vn/van-ban/bo-may-hanh-chinh/Van-ban-hop-nhat23-VBHN-VPQH-nam-2013-hop-nhat-Luat-giao-duc-220044.aspx>. Access in: the 15th Dec. 2016.

VIETNAM NATIONAL ASSEMBLY (2015), Vietnam's Law of Education. Available in: $\quad$ http://vietlaw.quochoi.vn/Pages/vbpq-toan-van.aspx?ltemID=27985>. Access in: the 15th Dec. 2016.

VIETNAM NATIONAL ASSEMBLY (2006), Vietnam's Law of Vocational Education Teaching. Available in: <ldtbxh.hatinh.gov.vn/uploads/laws/l76_2006_qh11_ dn.doc>. Access in: the 15th Dec. 2016.

VIETNAM NATIONAL ASSEMBLY (2014), Vietnam's Law of Vocational Education (2014), Available in: <http://www.molisa.gov.vn/Images/FileVanBan/LUAT74QH. pdf>. Access in: the 15th Dec. 2016.

VIETNAM MINISTRY OF EDUCATION AND TRAINING (2015), Vietnam system of education in several periods. Available in: <vanphong.moet.gov.vn/.../85f75f2 a2e6ca7e0090eab8.>. Access in: the 15th Dec. 2016.

VIETNAM MINISTRY OF INDUSTRY AND TRAde, The international commitments of the Free Trade Agreements (FTAs), Available in: <http://www.trungtamwto.vn/ $\mathrm{fta} / \mathrm{da}$-ky-ket>. Access in: the 15th Dec. 2016.

VIETNAM PRIME MINISTER (2012), Decision on ratifying the "Vietnam's Strategy for Developing the Education in the period 2011-2020". Available in: <HTTP:// WWW.DTHU.EDU.VN/MAINPAGE/DOCUMENTS/22.PDF>. ACCESS IN: THE 15TH DEC. 2016.

VIETNAM Prime Minister (2016), Decision 844/QĐ-TTg dated on the 18th May 2016 about "Ratifying the National Project "Supporting the National Start-up Innovation Ecosystem to the year 2025"". Available in: <http://www.most.gov.vn/ Attachments/34fb42317ebb48378800e5a0c3aa703f-Quyet\%20dinh\%20844_ QD_TTg.pdf>. Access in: the 14th Dec. 2016. 
Recebido em fevereiro de 2017

Aceito em setembro de 2017

NguyenThuong Lang é doutor. Professor da Universidade Nacional de Economia Vietnã, E-mail: langnguyen2200@gmail.com 